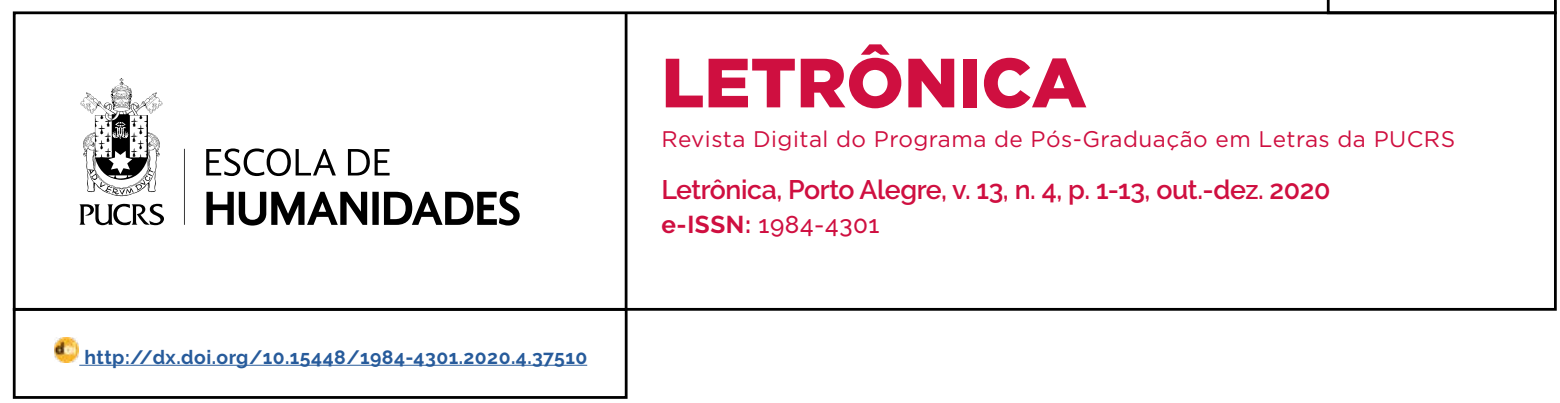

SEÇÃO: ARTIGOS

\title{
Práticas de literacia da informação em tempos de infodemia semiótica
}

\author{
Information literacy practices in times of semiotic infodemic
}

\section{Gabriela Fernanda Cé \\ Luft $^{1}$ \\ orcid.org/0000-0003-3540-9976 \\ gabiluft@gmail.com}

Filipe Xerxeneski da

Silveira ${ }^{2}$

orcid.org/0000-0001-6844-8467

lipexs@gmail.com

Recebido em: 31/3/2020.

Aprovado em: 22/7/2020.

Publicado em: 21/12/2020.
Resumo: Em uma era em que a informação é disponibilizada essencialmente em meios digitais, em que a leitura ocorre sobretudo em plataformas virtuais e em que leitores e escritores encontram-se globalmente conectados, o presente artigo evoca o conceito de literacia da informação. Para tanto, apresentam-se os conceitos de alfabetização, letramento e literacia, propostos por Lemos (2002), Pinto (2008) e Soares (2010). Posteriormente, contextualiza-se o fenômeno da desordem informacional, que conduz a um estado de infodemia semiótica. O fenômeno é ilustrado a partir da análise de notícias relacionadas à eclosão, no Brasil, do novo coronavirus, causador da COVID-19, no mês de março de 2020. Aponta-se para a necessidade de promoção de iniciativas voltadas ao desenvolvimento de competências que contribuam para a consolidação de práticas de literacia da informação, destinadas especialmente a professores e estudantes.

Palavras-chave: Literacia da informação. Notícias falsas. Desordem informacional. Infodemia semiótica. Covid-19.

Abstract: In an era where information is made available essentially on digital media, where reading occurs mainly on virtual platforms and where readers and writers are globally connected, this article evokes the concept of information literacy. For that, the concepts of initial reading instruction and literacy, proposed by Lemos (2002), Pinto (2008) and Soares (2010), are presented. Subsequently, the phenomenon of informational disorder is contextualized, which leads to a state of semiotic infodemic. The phenomenon is illustrated by the presentation of news related to the emergence, in Brazil, of the new coronavirus, which caused Covid-19, in March 2020. The text points to the need to promote initiatives for skills development that contribute to the consolidation of information literacy practices, aimed especially at teachers and students.

Keywords: Information literacy. Fake news. Informational disorder. Semiotic infodemic. Covid-19.

\section{Introdução}

Vivemos em uma era na qual fatos objetivos têm sido substituídos por opiniões e em que a formação da opinião pública é balizada por crenças pessoais. A natureza da verdade é modificada por emoções. Inverdades são aceitas, mesmo sendo sabidamente falsas, e decisões são tomadas a partir delas. Mesmo sem conhecimentos técnicos avançados, individuos tornam-se também produtores e difusores de informação, e não apenas consumidores. Contudo, a autonomia e a liberdade digitais demandam responsabilidade social, posto que dados imprecisos e informações enganosas ou errôneas, divulgadas sob uma infinidade de formas e disfarces, afetam 
a saúde e contribuem para a disseminação do ódio e da intolerância, entre outras consequências.

É nesse contexto que emerge a literacia da informação, cujo desenvolvimento revela-se como um atributo decisivo na sociedade contemporânea, indispensável para a autonomia da aprendizagem ao longo da vida. Compreender as responsabilidades e as implicações sociais que envolvem o uso da informação é de extrema importância, sobretudo em um universo permeado por pós-verdades.

Para abordar a temática, o artigo se organiza da seguinte forma: em um primeiro momento, resgatamos os conceitos de alfabetização, letramento e literacia, conforme distintas perspectivas teóricas (LEMOS, 2002; PINTO, 2008; SOARES, 2010). Posteriormente, contextualizamos o fenômeno da desordem informacional, que, por sua vez, conduz a um estado de infodemia semiótica, ilustrado com publicações a respeito da eclosão do novo coronavírus em território brasileiro durante o mês de março de 2020. Por fim, elencamos uma série de iniciativas, direcionadas especialmente a professores e estudantes, destinadas ao desenvolvimento de competências que contribuam para a consolidação de práticas de literacia da informação.

\section{Alfabetização, letramento e literacia: imbricamentos e diálogos possíveis}

Para além da alfabetização, que confere aos indivíduos o domínio dos processos de leitura e de escrita, a formação de leitores autônomos demanda o desenvolvimento e a consolidação de outras habilidades. No capítulo inicial da obra Letramento: um tema em três gêneros, Soares (2010) afirma que, no Brasil, pelo fato de "alfabetismo" não ser uma palavra corrente, ao buscar uma palavra que designasse aquilo que em inglês já se designava por literacy, optou-se por verter a palavra inglesa para o português, criando a palavra "letramento". Contudo, "curiosamente, em Portugal tem-se preferido o termo literacia, mais próximo ainda do termo inglês" (SOARES, 2010, p. 18, grifo da autora).

Temos, de um lado, uma abordagem cognitivo-psicológica, de sentido mais estrito: a al- fabetização está associada a um contexto de ensino e de aprendizagem dos processos de leitura e de escrita, ou seja, à aquisição das "tecnologias" do ler e do escrever; de outro, temos uma abordagem sociocultural, atrelada a um sentido mais lato, posto que visa identificar os processos subjacentes a essas capacidades, caso em que a literacia é vista como um processo social, desenvolvido a partir da exposição a práticas intimamente ligadas a contextos sociais e culturais (LEMOS, 2002). Em outras palavras, o letramento relaciona-se com a literacia em seu sentido lato, pois corresponde ao estado ou condição de quem, além de saber ler e escrever, também cultiva e coloca em exercício práticas sociais advindas do uso da escrita (SOARES, 2010). Ambos os sentidos são problematizados pelas áreas de Linguística e Educação desde a segunda metade da década de 1980.

Desde então, sua acepção alastrou-se para diferentes áreas: hoje, fala-se em letramento literário, letramento científico, letramento econômico, letramento tecnológico, letramento visual, letramento midiático, letramento em saúde etc. Configuram-se, pois, contextos multiletrados, com múltiplas formas de literacia. Consideramos, pois, o letramento como um fenômeno plural, dado que não existe apenas um tipo de letramento, mas letramentos, que vêm à tona conforme o avanço tecnológico e o desenvolvimento da sociedade. Tal concepção vai ao encontro da perspectiva que considera a língua não como única, homogênea, universal e atemporal, mas como intrinsicamente relacionada à complexidade dos tempos modernos.

Para Pinto (2008), a literacia corresponde a um processo de extração de sentidos de um texto, ou, ainda, de criar sentidos nos/para os textos. Implica habilidades e capacidades verbais diversas, como interpretar materiais visuais, desenvolver o pensamento crítico, usar e compreender conceitos matemáticos etc. (LEMOS, 2002). Nesse sentido, seu desenvolvimento é um processo constante e dinâmico, pois, diariamente, surgem novas agências, situações e eventos comunicativos, que exigem distintas práticas letradas, conforme as diferentes situações sociocomunicativas. 


\section{Literacia da informação, desordem informacional e infodemia semiótica}

Enquanto o jornalista e editor húngaro Joseph Pulitzer fazia uso de manchetes sensacionalistas e o escritor inglês George Orwell, em 1984. narrava a destruição de documentos por líderes partidários para eliminar as provas da mentira, as artimanhas atuais são mais eficientes: no lugar da destruição dos fatos, há a fabricação de histórias, as quais são exaustivamente repetidas até serem interpretadas como reais e apresentadas como produtos das tecnologias da informação. Notícias são compartilhadas não apenas para informar, mas também para persuadir.

Não estamos diante de um fenômeno novo. A novidade está na amplitude com que as notícias falsas podem se disseminar nas redes sociais. Conforme Fernández-García (2018), a perda de centralidade da fonte e a possibilidade de "viralização" diminuem muitas vezes o interesse pela veracidade da informação e a capacidade crítica de leitura para identificar o que é falso. Diversos acontecimentos recentes nos mostram que tais questões geram consequências políticas muito diretas.

Noticiários televisivos têm perdido audiência, especialmente entre as gerações mais jovens, que passaram a fazer uso das redes sociais como principal meio para a busca de informações. No Brasil, levantamento realizado pela Câmara dos Deputados e Senado em outubro de 2019, divulgado em dezembro do mesmo ano, mostra que $79 \%$ das pessoas utilizam o WhatsApp como fonte principal de informação, 49\% o YouTube e 44\% o Facebook (TORRES, 2019). Ou seja: notícias tradicionais estão perdendo terreno para novos formatos visuais, especialmente entre pessoas mais jovens.

Filtros invisiveis (filter bubble), presentes no Google e no Facebook, por exemplo, personalizam os conteúdos exibidos e impedem que pontos de vista contrários aos nossos, que poderiam ampliar ou questionar nossa visão de mundo, cheguem até nós, deixando-nos isolados em nossas próprias bolhas de informação, limitando o conteúdo informativo a que temos acesso (FERNÁNDEZ-GARCÍA, 2018). E é um algoritmo que determina a ordem das notícias que vemos nas redes sociais.
Já por meio das câmaras de ressonância (echo chambers), "informações, ideias e crenças são amplificadas por transmissão ou repetição em um sistema fechado em que visões diferentes ou alternativas são descartadas ou representadas de forma minoritária" (FERNÁNDEZ-GARCIA, 2018, p. 115). O resultado é que os cidadãos acabam consumindo notícias que se ajustam à sua própria linha de pensamento.

O atual contexto, caracterizado pelo desenvolvimento das tecnologias da informação e pela difusão massiva de informação, aponta para a necessidade de estímulo ao desenvolvimento de novas competências. É nessa conjuntura que ganha corpo a expressão literacia da informação, que engloba o conhecimento, as atitudes e o conjunto das capacidades necessárias para saber quando é necessária a informação e qual é a informação necessária, onde e como obtê-la, como avaliá-la criticamente, como organizá-la e como usá-la eticamente (GASQUE, 2010).

Há um excesso de informação, especialmente a que circula em formato digital, cada vez mais frequente e abundante. No entanto, essa abundância, traduzida na crescente disponibilidade e no acesso facilitado aos recursos informativos, não implica necessariamente uma melhoria da qualidade das informações obtidas. Se não for acompanhada de um conjunto de competências que permitam avaliar e selecionar os recursos disponiveis, o excesso de informação, por si só, não gera conhecimento. Nesse sentido, a literacia informacional resulta da necessidade de um uso crítico da informação.

Para Wardle e Derakhshan (2017, p. 20, tradução nossa), a desordem informacional pode ser caracterizada a partir de três diferentes noções: informações incorretas, desinformações e más informações. Enquanto a desinformação abrange informações falsas criadas deliberadamente para prejudicar pessoas, grupos sociais, organizações e países, as informações incorretas, apesar de falsas, não são criadas com a intenção de ocasionar danos. Por sua vez, as más informações também são usadas para gerar dados a pessoas, organizações e países; são, contudo, baseadas na realidade (ver Figura 1). 
Figura 1 - Os três tipos de desordem informacional

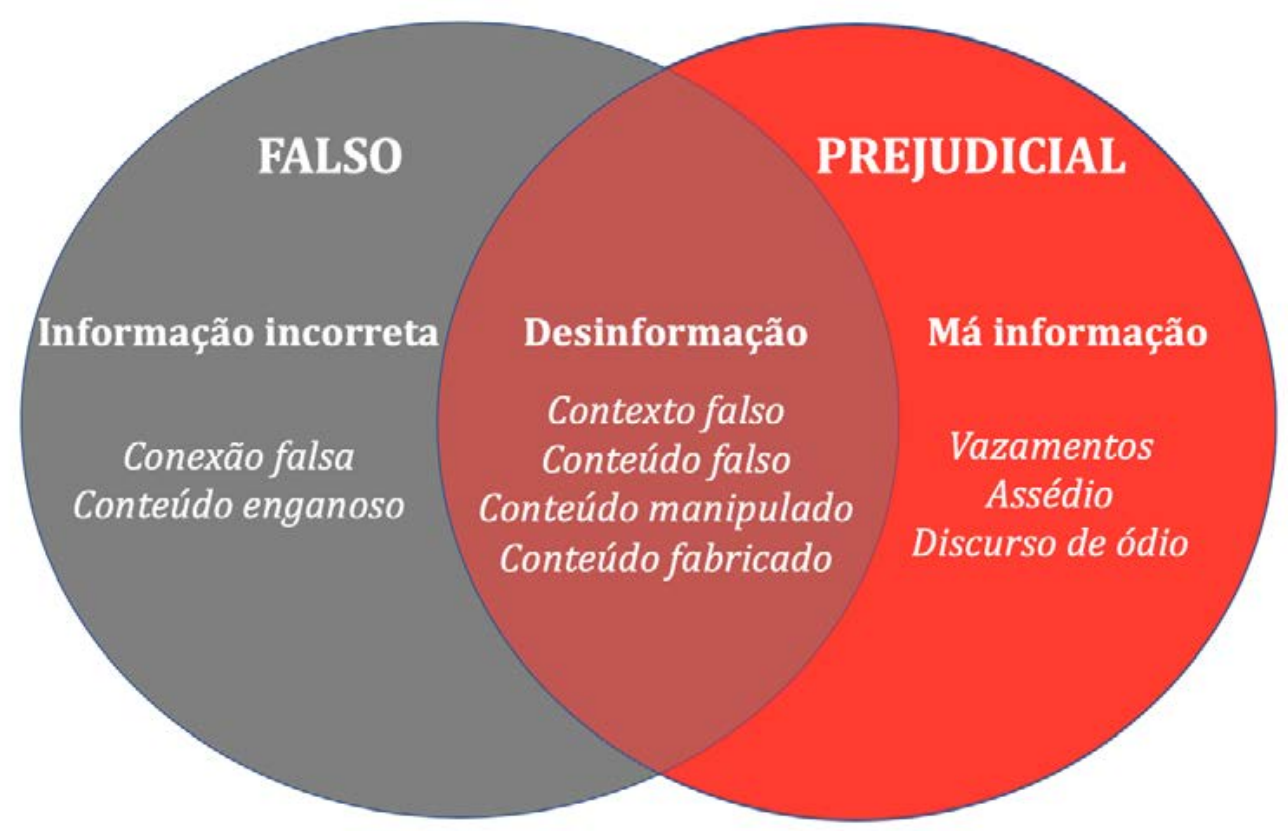

Fonte: reprodução de WARDLE; DERAKHSHAN (2017, p. 20, tradução nossa).

As autoras Marwick e Lewis (2017, p. 5), no livro Manipulação e desinformação da mídia online. abordam guerras informacionais e táticas de desordem informacional, apresentando quatro características definidoras do que chamam de manipulação midiática: 1) discurso deliberadamente ofensivo; 2) antipatia pelo sensacionalismo na grande mídia; 3) objetivo de criar impacto afetivo no público-alvo; e 4) ambiguidades, por meio de paródias que ocultam as intenções de autoria.

Estamos, contudo, diante de um tema relativamente novo, sobre o qual ainda pouco se pesquisou e publicou - o que é comprovado quando utilizamos a expressão de busca "desordem informacional" no Portal de Periódicos da Coordenação de Aperfeiçoamento de Pessoal de Nivel Superior (Capes) a fim de recuperar documentos indexados sobre o assunto. Em julho de 2020, o termo em português recuperou apenas um único registro, sem apresentar, porém, sua definição. Já a expressão de busca em inglês, "informational disorder", recuperou somente seis registros.

Para ilustrarmos parte dessa desordem informacional, evocamos a ascensão, no primeiro semestre de 2020, de um novo coronavirus, causador da COVID-19, responsável por infecções respiratórias potencialmente graves em alguns individuos. A cobertura midiática, por vezes, transformou-se em uma batalha de versões. A teoria conspiratória inicial, de que se tratava de uma "arma bioquímica criada em laboratório secreto" (DENCK, [2020]), foi suplantada, em um primeiro momento, pela adoção do termo "epidemia". Pouco tempo depois, por recomendação da Organização Mundial da Saúde (OMS), decretou-se que, na realidade, estávamos diante de uma "pandemia", dada a disseminação da doença por uma grande quantidade de regiões do globo.

Contudo, na chamada "guerra da informação", materializada mediante o controle e a manipulação da opinião pública por meio da comunicação midiática, com o objetivo de fazer uso do discurso para influenciar populações, o novo coronavírus se revelou como uma "infodemia" com alto rendimento semiótico (FERREIRA, 2020). A palavra infodemics foi incorporada ao vocabulário da saúde pública em 2018. Em obra publicada pela OMS, o termo é cunhado como

a rápida disseminação de informações de todos os tipos, incluindo rumores, fofocas $e$ informações não confiáveis, que se espalham instantânea e internacionalmente por meio do crescente uso popular de telefones celulares, redes sociais, internet e outras tecnologias de 
comunicação. Além disso, há a proliferação de "especialistas" baseados na web, com pontos de vista diversos e muitas vezes contraditórios, que podem causar confusão, ansiedade e até pânico [...]. Essas informações falsas ou enganosas podem ocasionar uma relutância pública generalizada em relação à tomada de medidas promovidas por autoridades sanitárias para o controle de infecções e, assim, atrasar intervenções essenciais (WHO, 2018, p. 26, tradução nossa).

De acordo com uma nota informativa da Organização Pan-Americana da Saúde (OPAS), a infodemia tem o potencial de piorar a pandemia, pois: a) dificulta a localização de fontes e orientações confiáveis; b) gera ansiedade, depressão, sobrecarga e exaustão emocional; c) afeta os processos de tomada de decisão, quando são esperadas respostas imediatas e não há tempo suficiente para a análise de dados científicos; e d) não confere um controle de qualidade no que é publicado e, às vezes, também, nas informações usadas para agir e tomar decisões (OPAS, 2020).

John Zarocostas, jornalista australiano que cobre noticias de saúde mundial e escreve editoriais para renomados periódicos internacionais, publicou, na conceituada revista The Lancet, em fevereiro de 2020, um editorial intitulado "How to fight an infodemic". No texto, enfatiza que a infodemia refere-se a um grande aumento de informações falsas e pode se tornar exponencial em um curto período de tempo, fenômeno que, na era da desinformação, é amplificado, espalhando-se ainda mais rapidamente, como um virus (ZAROCOSTAS, 2020).

Assim como no caso da expressão "desordem informacional", estamos, mais uma vez, diante de um termo bastante recente. Ao realizarmos uma pesquisa nas bases de dados do Portal de Periódicos da Capes - Lilacs, Bireme, PubMed e Web of Science -, por meio dos descritores em português e inglês, respectivamente, "infodemia", "infodemia semiótica", "infodemic" e "semiotic infodemic", chegamos aos seguintes resultados: o descritor em português "infodemia" recuperou nove registros, embora nenhum deles no idioma original português; a expressão de busca "infodemia semiótica" não recuperou nenhum registro nas bases consultadas; o termo em inglês "infodemic" recuperou 40 registros, todos de 2020, sendo 28 relativos a artigos publicados em periódicos com revisão por pares; por fim, a expressão de busca "semiotic infodemic" não recuperou um único registro nas bases de dados pesquisadas. Estamos, portanto, diante de um fenômeno e de uma expressão sobre os quais pouco se escreveu.

Os conceitos de desordem informacional e infodemia aplicam-se, pois, ao contexto da eclosão da COVID-19 no Brasil: deparamo-nos com uma infinidade de informações falsas, geralmente de cunho negativo, cujos dados errôneos e equivocados são transmitidos, especialmente, via redes sociais, causando, entre outros sintomas, aflição e pânico. Neste cenário, não há tempo para se adaptar ao que é veiculado, pois logo surgem novos indícios. A enfermidade é vivida em tempo real e as informações tornam-se pereciveis. Governos dividem-se entre alertar sobre a gravidade da doença e tentar impedir o pânico entre a população. Os impactos dessa avalanche informacional são inúmeros e não se refletem apenas na saúde mental: prateleiras de supermercados foram rapidamente esvaziadas e pessoas correram às farmácias em busca de medicamentos sem evidências científicas de real eficácia no tratamento do novo coronavirus.

Um fenômeno linguístico sintomático desse cenário movediço é a quantidade significativa de notícias publicadas sobre o assunto que fazem uso de conjunções adversativas, utilizadas para conectar orações, a fim de que seja estabelecida uma relação de contraste. Em determinado trecho de matéria intitulada "Brasil tem 25 mortes e 1.546 casos confirmados de coronavírus" (Figura 2), publicada pelo jornal Folha de S. Paulo em 22 de março de 2020, lê-se: 
Figura 2 - Trecho da notícia "Brasil tem 25 mortes e 1.546 casos confirmados de coronavírus"

Além disso, o ministro disse que acredita que as igrejas podem continuar abertas, mas pediu a pastores e padres que evitem aglomerações de pessoas.

"Não vejo problema de a igreja ficar de porta aberta", afirmou.

Fonte: BOLDRINI (2020).

Acerca dos sintomas previstos nos infectados com a COVID-19, em 26 de março de 2020, na publicação
"Perda de olfato pode indicar infeção pelo novo coronavirus", a Folha de S. Paulo informa (Figura 3):

Figura 3 - Trecho da notícia "Perda de olfato pode indicar infecção pelo novo coronavírus"

De acordo com Geraldo Druck Sant'Anna, diretor-presidente da ABORL, uma equipe de membros da sociedade se reuniu para fazer uma revisão dos relatos que estavam aparecendo pelo mundo e juntar evidências. "Não temos um número de casos suficiente para dizer se isso é uma verdade absoluta. A Doença é nova e ainda estamos aprendendo sobre ela, mas essa é uma recomendação prudente", disse.

Fonte: BATISTA (2020)

No entanto, talvez o caso mais emblemático do conflito de informações, com graves consequências e, especialmente, de interesses políticos e financeiros, tenha ocorrido a partir da divulgação, por certos governantes, especialmente Donald Trump e Jair Bolsonaro, presidentes norte-americano e brasileiro, respectivamente, do êxito da cloroquina, medicamento utilizado em determinadas regiões para a profilaxia de malária, para o tratamento da COVID-19. Parte do imbróglio foi exposto em matéria intitulada "Afinal, cloroquina funciona como tratamento para o coronavirus?" (Figura 4), publicada pelo Jornal Metro em 25 de março de 2020 :

Figura 4 - Trecho da notícia "Afinal, cloroquina funciona como tratamento para o coronavírus?"

Contudo, a o próprio FDA, agência americana de Administração de Alimentos e Medicamentos, emitiu uma declaração dizendo que o medicamente está apenas em testes de laboratório e que, portanto, seu uso em pacientes com coronavírus ainda não foi autorizado ou recomendado.

\section{CLOROQUINA FUNCIONA COMO TRATAMENTO PARA O CORONAVÍRUS?}

A agência americana de Administração de Alimentos e Medicamentos acredita que o medicamente pode ter potencial contra o novo coronavírus.

Contudo, ainda será necessário passar por cuidadosos testes para determinar se ele realmente é eficaz. Ou seja, ainda não há qualquer comprovação.

Fonte: MARQUES (2020).

As consequências da disseminação de informações sem comprovação científica podem ser potencialmente perigosas - sobretudo em assuntos da área da saúde, que demandam evidências da vigilância epidemiológica, ou seja, a aplicação de métodos científicos às práticas médicas. Neste caso em particular, após escutar a fala do presidente de seu país, a ingestão da cloroquina 
levou um norte-americano ao óbito. Na Nigéria, dois casos de envenenamento foram reportados (MACKEY, 2020). No Brasil, a corrida às farmácias fez com que pacientes com doenças autoimunes e com artrite passassem a ter dificuldades para encontrar o medicamento (MENGUE; DURÃO;
JANSEN, 2020). Os acontecimentos são emblemáticos das consequências dos fenômenos de desordem informacional e infodemia. Os efeitos colaterais do uso de remédios sem supervisão médica podem ser graves, conforme alertado por matéria divulgada pelo jornal Nexo (Figura 5):

Figura 5 - Trecho da notícia "Coronavírus: os perigos de usar remédios sem supervisão"

\section{Coronavírus: os perigos de usar remédios sem supervisão}

Camilo Rocha 24 de mar de 2020 (atualizado 27/03/2020 às 14h13)

Após Trump e Bolsonaro mencionarem medicamento usado em estudos iniciais sobre o tratamento da covid-19, houve corrida para as farmácias. Efeitos colaterais, no entanto, podem ser graves

Fonte: ROCHA (2020).

Debates sobre os diferentes tipos de isolamentos possiveis também vieram à tona. Em 26 de março, o jornal Gazeta, em matéria intitulada "Coronavírus: as diferenças entre isolamento vertical e horizontal", problematizou as possiveis consequências da adoção de um modelo de isolamento vertical (Figura 6):

Figura 6 - Trecho da notícia "Coronavírus: as diferenças entre isolamento vertical e horizontal"

Este método de isolamento, segundo Rodrigues, tem um impacto econômico menor, já que mantém atividades funcionando. Contudo, pode ter um efeito desastroso nos hospitais. No Reino Unido, ao perceber um aumento do número de pessoas infectadas e possível colapso do sistema de saúde, o governo optou pelo fechamento de escolas e suspensão de outras atividades.

Fonte: DINIZ (2020).

Para o contexto brasileiro, no entanto, o isolamento horizontal seria mais eficaz para a interrup- ção da cadeia de transmissão do vírus (Figura 7):

Figura 7 - Trecho da notícia "Coronavirus: as diferenças entre isolamento vertical e horizontal" A medida adotada na Coréia do Sul, contudo, não seria bem sucedida no Brasil, segundo Rodrigues. Para ele, em países como o nosso, onde não se obtém um diagnóstico rápido e há uma grande diversidade populacional, adotar o isolamento horizontal é a forma mais eficaz para interromper a cadeia de transmissão do vírus.

Fonte: DINIZ (2020).

O uso reiterado dos conectivos "mas", "porém", "contudo", "entretanto" etc., evidencia que grande parte do que foi noticiado não se tratava de informação baseada em evidências, mas, pura e simplesmente, de especulação, de conjecturas infundadas e, por vezes, maldosas. Assim, o rendimento semiótico da COVID-19 passa a torná-lo um evento midiático (FERREIRA, 2020), a partir da diversa gama de significações que passa a gerar, de acordo com a intencionalidade do emissor do discurso e do interesse do veículo de comunicação que propaga a informação.

Há uma série de microprocessos imbrincados na construção do tecido textual (escolha de tempos verbais, uso de conjunções, processos de referenciação anafórica e catafórica etc.) que, a fim de que sejam devidamente reconhecidos e manipulados e possibilitem o desenvolvimento da competência 
linguística, necessitam de intervenção pedagógica.

Afora as notícias destinadas a orientar acerca de procedimentos rotineiros, sejam eles sociais ou relacionados a hábitos de saúde propriamente ditos, a eclosão de uma enfermidade de tal magnitude é terreno fértil não apenas para o fomento de dúvidas e de incertezas, mas, também, para a atuação de oportunistas. Em cidades inteiras submetidas à quarentena doméstica, é natural que seus habitantes passem a utilizar intensamente redes sociais, o que facilita a disseminação de boatos, medos e atitudes discriminatórias, conforme atesta a matéria da Figura 8.

Figura 8 - Trechos da notícia "'Auxilio coronavírus' e outros golpes no WhatsApp atingem 2 milhões"

\title{
'Auxílio coronavírus' e outros golpes no WhatsApp atingem 2 milhões
}

\begin{abstract}
Textos falsos prometem "auxilio coronavirus" e álcool em gel no WhatsApp
É um exemplo o suposto programa de "Auxílio Cidadão 2020", que alega que trabalhadores autônomos e pessoas de baixa renda têm direito a uma espécie de "auxílio coronavírus" de $\mathrm{R} \$ 200$ mensais. Para isso, a vítima teria que fazer cadastro em um site que é, na verdade, um link malicioso.

A corrente passou a ser compartilhada em grupo de WhatsApp neste domingo (22) e foi desmentida no mesmo dia pela Secretaria Especial do Desenvolvimento Social. O golpe se aproveita de medidas anunciadas nos últimos dias pelo governo, mas que ainda não foram aprovadas e, portanto, não estão em vigor.

Outras mensagens que circulam nas redes sociais contém fake news sobre a situaçāo da pandemia do novo coronavírus. Segundo pesquisa do dfndr lab, cerca de 42,5 milhões de brasileiros já receberam ou acessaram notícias falsas sobre a Covid-19. Para 43,2\% dos entrevistados, o WhatsApp é o principal vetor para os boatos.
\end{abstract}

Fonte: FRANCO (2020).

O número é alarmante: estima-se que $85 \%$ das mensagens sobre a COVID-19 checadas pelo Ministério da Saúde sejam falsas (Figura 9).

Figura 9 - Trecho da notícia "Fake news atingem $85 \%$ das mensagens sobre coronavirus checadas pelo Ministério da Saúde"

\section{Fake news atingem $85 \%$ das mensagens sobre coronavírus checadas pelo Ministério da Saúde}

Poder curativo de vitaminas e chás e teorias da conspiraçăo estăo entre as dúvidas enviadas pela populaçăo
Se antes epidemias eram combatidas com médicos, enfermeiros, medicamentos e hospitais, a revolução tecnológica, a globalização social e a explosão demográfica alteraram esse quadro. Por mais que a ciência moderna, por meio de conhecimentos, dinheiro e equipamentos para pesquisa possa desenvolver com relativa rapidez uma vacina contra o novo coronavírus, o que geraria relativa tranquilidade, observamos um aumento acelerado de condutas irracionais, geralmente alimentadas pelo medo, evidenciando que o contágio do pânico é muito mais veloz do que a transmissão física do vírus, conforme denota a seguinte manchete (Figura 10): 
Figura 10 - Trecho da notícia "Após fake news, venda de vinagre cresce $94 \%$ em supermercados, diz pesquisa"

\section{Após fake news, venda de vinagre cresce $94 \%$ em supermercados, diz pesquisa}

Circulou pela internet informação de que produto impediria a transmissăo do coronavírus

Fonte: CUNHA (2020).
Condutas irracionais costumam ser alimentadas pelo desconhecimento; nesse sentido, para coibir o pânico social, o mais indicado é a informação - nem que para isso sejam utilizados robôs (os chamados bots) - Figura 11:

Figura 11 - Trecho da notícia "Contra fake news, Ministério da Saúde cria robô sobre Covid-19 no WhatsApp

\title{
Contra fake news, Ministério da Saúde cria robô sobre covid-19 no WhatsApp
}

\author{
Para aumentar o alcance de informações verificadas sobre a covid-19, Ministério da \\ Saúde lança bot para o WhatsApp
}

Fonte: CURY (2020).

A sociedade planetária globalizada é impelida a lidar com uma enfermidade cujo combate depende essencialmente da informação, em um momento em que ainda não se sabe como lidar com a pandemia no dia a dia. A doença, temida mundialmente, também contaminou a disseminação de informações em um mundo digitalmente interconectado. Assim, a primeira grande infodemia da nova era digital advém dessa disparidade entre informação e desinformação. Para combatê-la, vacinas e hospitais são insuficientes. Como lidar com a informação em situações criticas, em que as pessoas são confrontadas com o desconhecimento?

\section{Ações e iniciativas para o fomento de práticas de literacia da informação}

Em um cenário em que a desconfiança em relação à mídia aumenta cada vez mais - o Relatório de Situação de Midia de 2019, realizado pela Cision, aponta que 63\% dos entrevistados (dois mil jornalistas de dez paises, incluindo o Brasil) sentiram perda de confiança do público em 2019 (PR NEWSWIRE, 2019) -, que ações estratégicas podem ser adotadas por professores e profissionais da informação para o combate às fake news?

Empresas como Google e Facebook têm se mo- bilizado para evitar que suas plataformas sejam utilizadas por sites que divulgam noticias falsas. Está entre os objetivos do Facebook Journalism Project, por exemplo, lançado em janeiro de 2017, auxiliar os cidadãos a obterem as informações necessárias para decidir em quais fontes acreditar. Em abril do mesmo ano, o News Integrity Initiative foi lançado por grandes nomes da tecnologia, fundações sem fins lucrativos e universidades norte-americanas, com o objetivo de coibir a proliferação de notícias falsas pela internet (COHEN, 2017).

Em agosto de 2018, a International Federation of Library Associations and Institutions (IFLA) manifestou sua preocupação pelo impacto público desproporcionado que o fenômeno das fake news vinha assumindo face à liberdade de expressão e ao acesso à informação. O órgão defende que qualquer restrição a essa liberdade, mediante a censura ou o bloqueio de acesso aos recursos digitais e à internet, deve ser limitada, e desafia os governos a criarem e investirem em programas de literacia da informação e literacia midiática, em especial, por meio de escolas e bibliotecas. Criou um infográfico, que indica oito etapas simples para a verificação da confiabilidade de noticias. Além disso, estimulou que o material fosse impresso, traduzido e compartilhado (Figura 12). 
Figura 12 - Infográfico "Como identificar notícias falsas"

\section{COMO IDENTIFICAR N TÍCIAS FALSAS}

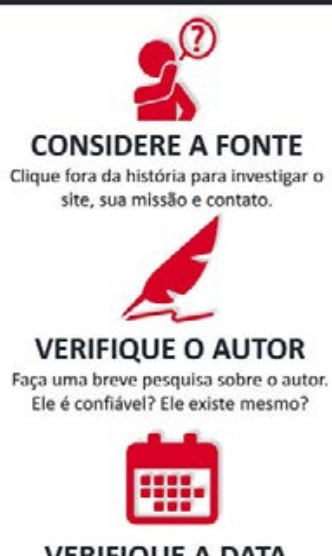

\section{VERIFIQUE A DATA}

Repostar notícias antigas não significa que sejam relevantes atualmente.

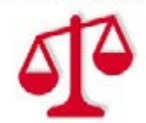

É PRECONCEITO?

Avalie se seus valores próprios e crenças podem afetar seu julgamento.

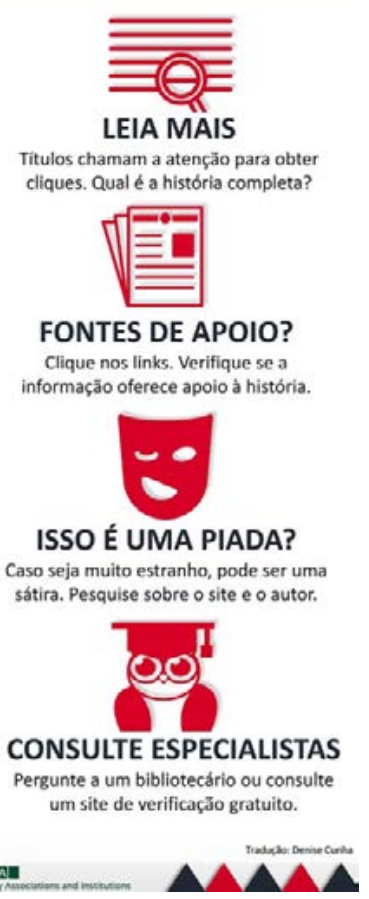

Fonte: INTERNATIONAL FEDERATION OF LIBRARY ASSOCIATIONS AND INSTITUTIONS (2018).

A American Library Association (ALA), por sua vez, tem reafirmado a importância de se combater todas as formas de distorção da verdade informativa, ressaltando, entre outras estratégias, o desenvolvimento de competências da literacia da informação como ferramenta para a localização e a validação de fontes fidedignas. No caso específico da COVID-19, criou uma página com o intuito de oferecer recursos com exemplos de como as bibliotecas têm atuado não apenas no combate à disseminação de notícias falsas, mas também contra o racismo e a xenofobia relacionados ao tema (AMERICAN LIBRARY ASSOCIATION, 2020).

No Brasil, também foram desenvolvidos mecanismos que podem ser utilizados para a verificação da confiabilidade da informação, com vistas ao combate à desinformação no ambiente digital. Quanto a algoritmos e a aplicativos, há um detector de bots (https://pegabot.com.br), que tem por objetivo verificar perfis em redes sociais, pontuando a probabilidade de estarmos diante de bots, ou seja, robôs. Também há um site destinado a detectar fake News, ${ }^{3}$ financiado pelo Conselho Nacional de Desenvolvimento Científico e Tecnológico (CNPq) e pela Capes, cujo sistema aplica métodos para extrair atributos linguisticos de textos, utilizando-os em um modelo de aprendizado de máquina, que classifica as notícias como verdadeiras ou falsas.

Já no campo educacional, muitas são as ferramentas que podem auxiliar professores a promoverem práticas de literacia da informação junto a seus alunos. O Quadro 1 sintetiza algumas dessas iniciativas destinadas à avaliação da credibilidade das informações:

Quadro 1 - Projetos para a promoção da literacia informacional

\begin{tabular}{|l|l|}
\hline \multicolumn{1}{|c|}{ Projeto e link para acesso } & \multicolumn{1}{c|}{ Objetivo } \\
\hline $\begin{array}{l}\text { - Digital Polarization Initiative } \\
\text { (Digipo) } \\
\text { https://digipo.io }\end{array}$ & $\begin{array}{l}\text { Conscientizar os jovens sobre o conteúdo informativo que eles encon- } \\
\text { tram na internet, fazendo-os participar da análise de questões relacio- } \\
\text { nadas com a polarização digital. }\end{array}$ \\
\hline $\begin{array}{l}\text { - Project Look Sharp } \\
\text { https://projectlooksharp.org }\end{array}$ & $\begin{array}{l}\text { Desenvolver e fornecer planos de estudo, materiais, formação e apoio } \\
\text { para a integração da literacia da informação ao curriculo escolar em } \\
\text { todos os niveis educacionais. }\end{array}$ \\
\hline $\begin{array}{l}\text { - News Literacy Project } \\
\text { https://newslit.org }\end{array}$ & $\begin{array}{l}\text { Capacitar os educadores a ensinarem seus alunos as habilidades neces- } \\
\text { sárias para se tornarem consumidores inteligentes e ativos de notícias e } \\
\text { outras informações e a diferenciarem fatos de ficção na era digital. }\end{array}$ \\
\hline
\end{tabular}




\begin{tabular}{|c|c|}
\hline Projeto e link para acesso & Objetivo \\
\hline $\begin{array}{l}\text { - Mind Over Media } \\
\text { https://mediaeducationlab.com }\end{array}$ & $\begin{array}{l}\text { Analisar a propaganda e ajudar os cidadãos a desenvolverem as com- } \\
\text { petências necessárias e resistirem a ela, promovendo diálogos e deba- } \\
\text { tes sobre o que a constitui e como ela pode afetar de forma positiva ou } \\
\text { negativa os indivíduos e a sociedade como um todo. }\end{array}$ \\
\hline $\begin{array}{l}\text { - Student Reporting Labs } \\
\text { https://studentreportinglabs.org }\end{array}$ & $\begin{array}{l}\text { Criar experiências educacionais transformadoras por meio da produção de } \\
\text { vídeos, que conectam estudantes do ensino médio com suas comunidades. }\end{array}$ \\
\hline $\begin{array}{l}\text { - Civic Online Reasoning } \\
\text { https://cor.stanford.edu }\end{array}$ & $\begin{array}{l}\text { Disponibilizar planos de aulas e avaliações gratuitas, com o intuito de } \\
\text { auxiliar educadores a ensinarem seus alunos a avaliarem informações } \\
\text { online, a partir de três questionamentos: quem está por trás da informa- } \\
\text { ção? Qual é a evidência? O que dizem outras fontes? }\end{array}$ \\
\hline
\end{tabular}

Fonte: elaborado pelos autores (2020).

A comprovação da veracidade das notícias é essencial em um ecossistema midiático em que a mentira é institucionalizada a partir de uma sobrecarga de informações e de uma grande quantidade de fontes. Outra iniciativa que pode ser elencada é o chamado fact-checking (verificação de informações), por meio de sites voltados à comprovação da veracidade das notícias, caso, no Brasil, da Agência Lupa, ${ }^{4}$ e do Aos Fatos, ${ }^{5}$ site jornalístico independente de verificação de fatos.

Porém, tais medidas não são suficientes. Se as novas gerações obtêm suas informações por meio de redes sociais e outros recursos disponíveis na internet, elas devem aprender a interpretar e criticar o que leem. Aos professores, ficam alguns questionamentos: por que não oferecer a crianças e jovens as ferramentas necessárias para avaliar a credibilidade das informações e fazê-lo com uma perspectiva crítica? Não seriam as fake news uma oportunidade para a propulsão do desenvolvimento da literacia informacional?

\section{Considerações finais}

O conceito de literacia atualiza necessidades da sociedade contemporânea em relação às competências de leitura. Quando nos falta a capacidade de compreender, analisar, refletir, interpretar, inter-relacionar informações, tornamo-nos muito mais limitados a atuar em sociedade e a exercer nossos direitos. Fazer uso social da leitura e da escrita, refletir e desenvolver um pensamento crítico, processar, sintetizar e saber avaliar uma dada informação são habilidades fundamentais na sociedade atual. A literacia é, assim, condição para o exercício da cidadania e uma exigência da própria democracia; seu domínio é essencial para a não exclusão.

A infodemia, propulsora de fake news produzidas em determinados contextos históricos por pessoas e/ou grupos que detêm interesses específicos, não é controlável com a censura, mas precisamente com mais formação em fontes de informação. É função primordial da escola possibilitar aos alunos ferramentas para que analisem criticamente as informações, verifiquem como elas foram elaboradas e por quem, com quais objetivos, se apresentam distorções e como podem ser manipuladas. Nesse sentido, instituições de ensino devem direcionar esforços para que seus alunos saibam pesquisar, recuperar, avaliar e utilizar devidamente as informações de que necessitam, tenham consciência de suas necessidades de informação, saibam realizar pesquisas eficientes, interpretem dados e avaliem o valor das suas fontes. Porém, essas são incumbências que extrapolam o ambiente escolar e a academia:

Estudantes, professores, investigadores, bem como o cidadão comum, devem saber qual a informação de que necessitam, conseguir identificar o que procuram, reconhecer as condições sob as quais a informação pode 
ser reutilizada de forma ética, assim como o destino que terá, e distinguir entre conhecimento, opinião e comentário (ANTUNES; LOPES; SANCHES, 2019, p. 5).

Plataformas de redes sociais são vetores de comportamentos de desordem informacional. Nunca foi tão necessário capacitar os cidadãos e lhes possibilitar a aquisição de competências midiáticas para acessar, compreender, analisar, avaliar e produzir conteúdo, além de distinguir entre notícias verdadeiras e falsas. A luta contra a desinformação se dá por meio da realização de ações direcionadas para o desenvolvimento do pensamento crítico e de competências para a avaliação das fontes de informação. E isso deve ser feito por meio de estratégias que fomentem práticas de literacia da informação, capazes de reforçar a democracia e de formar cidadãos informados e aptos a decidir livremente.

\section{Referências}

AMERICAN LIBRARY ASSOCIATION (ALA). Libraries Respond: Combating Xenophobia and Fake News in light of COVID-19. 2020. Disponivel em: http://www.ala.org/ advocacy/libraries-respond-combating-xenophobia-and-fake-news-light-covid-19. Acesso em: 27 mar. 2020.

ANTUNES, Maria da Luz; LOPES, Carlos; SANCHES, Tatiana. A literacia da informação no combate às fake news: desafios e estratégias formativas no ensino superior. In: ENCUENTRO IBÉRICO EDICIC, 11., Barcelona, jul. 2019. Anais [...]. Barcelona; EDICIC, 2019. Disponivel em: https://doi.org/10.31229/osf.io/3sbwa. Acesso em: 27 mar. 2020. https://doi.org/10.31229/osf.io/3sbwa

BATISTA, Everton Lopes. Perda de olfato pode indicar infecção pelo novo coronavírus. Folha de S. Paulo, São Paulo, 26 mar. 2020. Disponivel em: https://WwW1.folha.uol.com.br/equilibrioesaude/ 2020/03/perda-de-olfato-pode-indicar-infeccao-pelo-novo-coronavirus.shtml. Acesso em: 25 mar. 2020.

BOLDRINI, Angela. Brasil tem 25 mortes e 1.546 casos confirmados de coronavirus. FoLha de S. Paulo, São Paulo, 22 mar. 2020. Disponivel em: https://www1.folha.uol.com.br/ equilibrioesaude/2020/03/brasil-tem-25-mortes-e-1546-casos-confirmados-de-coronavirus.shtml. Acesso em: 23 mar. 2020.

CANCIAN, Natália. Fake news atingem $85 \%$ das mensagens sobre coronavirus checadas pelo Ministério da Saúde. Folha de S. Paulo, São Paulo, 29 fev. 2020. Disponivel em: https://Www1. folha.uol.com.br/equilibrioesaude/2020/02/ fake-news-atingem-85-das-mensagens-sobre-coronavirus-checadas-pelo-ministerio-da-saude.shtml. Acesso em: 30 mar. 2020.
COHEN, David. The News Integrity Initiative Launches With Facebook as One of Its Founding Funders. Adweek, Nova lorque, 03 abr. 2017. Disponivel em: https://www. adweek.com/digital/news-integrity-initiative/. Acesso em: 20 mar. 2020.

CUNHA, Joana. Após fake news, venda de vinagre cresce 94\% em supermercados, diz pesquisa. Folha de S. Paulo, São Paulo, 23 mar. 2020. Disponivel em:https:// www1.folha.uol.com.br/colunas/painelsa/2020/03/ apos-fake-news-venda-de-vinagre-cresce-94-em-supermercados-diz-pesquisa.shtml. Acesso em: 25 mar. 2020.

CURY, Maria Eduarda. Contra fake news, Ministério da Saúde cria robô sobre Covid-19 no WhatsApp. Exame, São Paulo, 27 mar. 2020. Disponivel em: https://exame.abril.com.br/ciencia/contra-fakenews-ministerio-da-saude-cria-bot-sobre-covid -19-no-whatsapp/. Acesso em: 29 mar. 2020.

DENCK, Diego. Virus alienígena e arma biológica: as teorias conspiratórias da Covid-19. TecMundo, 20 mar. 2020. Disponivel em: https://www.tecmundo.com.br/ciencia/ 151284-virus-alienigena-arma-biologica-teoriasconspiratorias-covid-19.htm. Acesso em: 23 mar. 2020.

DINIZ, lara. Coronavirus: as diferenças entre isolamento vertical e horizontal. A Gazeta, Vitória, 26 mar. 2020. Disponivel em: https://www.agazeta.com.br/es/gv/ coronavirus-as-diferencas-entre-isolamentohorizontal-e-vertical-0320. Acesso em: 27 mar. 2020.

FERREIRA, Wilson Roberto Vieira. Coronavirus: epidemia? Pandemia? Ou infodemia semiótica? Rio de Janeiro: Centro de Estudos Estratégicos da Fiocruz (CEE), 03 mar. 2020. Disponivel em: https://cee.fiocruz.br/?q=node/1130. Acesso em: 20 mar. 2020

FERNÁNDEZ-GARCÍA, Nuria. Fake news: uma oportunidade para a alfabetização midiática. Nueva Sociedad, Buenos Aires, jul. 2018. Disponivel em: https://nuso. org/media/articles/downloads/7.TC_Fernandez_Garcia_EP18.pdf. Acesso em: 24 mar. 2020

FRANCO, Marcela. "Auxílio coronavírus" e outros golpes no WhatsApp atingem 2 milhões. TechTudo, 23 mar. 2020. Disponivel em: https://www. techtudo.com.br/noticias/2020/03/auxiliocoronavirus-e-outros-golpes-no-whatsappatingem-2-milhoes.ghtml. Acesso em: 25 mar. 2020.

GASQUE, Kelley Cristine Gonçalves Dias. Arcabouço conceitual do letramento informacional. Ciência da Informação, Brasília, DF, v. 39, n. 3, set./dez. 2010. https://doi.org/10.1590/S0100-19652010000300007

INTERNATIONAL FEDERATION OF LIBRARY ASSOCIATIONS AND INSTITUTIONS (IFLA). How to spot fake news. 2018. Disponivel em: https://www.ifla.org/ publications/node/11174. Acesso em: 29 mar. 2020.

LEMOS, Marion de. Closing the gap between research and practice: foundations for the acquisition of literacy. Melbourne: Australian Council for Educational Research (ACER), 2002.

MACKEY, Robert. Coronavirus: motivado por Trump, americano toma produto com cloroquina e morre. The Intercept Brasil, 30 mar. 2020. Disponivel em: https://theintercept.com/2020/03/30/ coronavirus-trump-cloroquina-americano-morre/. Acesso em: 30 mar. 2020. 
MARQUES, Nathalia. Afinal, cloroquina funciona como tratamento para o coronavirus? Metro Jornal, Porto Alegre, 25 mar. 2020. Disponivel em: https://WwW.metrojornal.com.br/ coronavirus-covid-19/2020/03/25/afinal-cloroquinafunciona-para-combater-o-coronavirus.html. Acesso em: 26 mar. 2020

MARWICK, Alice; LEWIS, Rebecca. Media manipulation and disinformation online. New York: Data \& Society Research Institute, 2017.

MENGUE, Priscila; DURÃO, Mariana; JANSEN, Roberta. Corrida por cloroquina, testado para coronavirus, afeta tratamento de outras doenças. $O$ Estado de S. Paulo, São Paulo, 20 mar. 2020. Disponivel em: https://saude.estadao.com.br/noticias/ geral,corrida-por-remedio-afeta-tratamento-de-outras-doencas,70003242254. Acesso em: 30 mar. 2020.

ORGANIZAÇÃO PAN-AMERICANA DA SAÚDE (OPAS). Entender la infodemia y la desinformación en la lucha contra la COVID-19. Disponivel em: https:// iris.paho.org/bitstream/handle/10665.2/52053/ Factsheet-Infodemic_spa.pdf?sequence $=14$. Acesso em: 23. jul. 2020

ORWELL, George. 1984. São Paulo: Companhia das Letras, 2009

PINTO, Maria da Graça L. Castro. A literacia e o enveIhecimento cognitivo. In: PINTO, Maria da Graça L. Da aprendizagem ao longo da vida ou do exemplo de uma relação ternária: agora, antes, depois. Porto: Faculdade de Letras da Universidade do Porto, 2008. p. 79-114. Disponivel em: https://ler.letras.up.pt/uploads/ficheiros/8215.pdf. Acesso em: 20 mar. 2020.

PR NEWSWIRE. De fake news à queda de credibilidade: pesquisa aponta desafios enfrentados pelo jornalismo atual. Associação Nacional de Editores de Revistas (ANER), 27 jun. 2019. Disponivel em: https://WwW.aner.org.br/anj-aner-informativo/de-fake-news-a-queda-de-credibilidadepesquisa-aponta-desafios-enfrentadospelo-jornalismo-atual.html. Acesso em: 19 mar. 2020.

ROCHA, Camilo. Cloroquina: os perigos de usar remédios sem supervisão. Nexo, São Paulo, 24 mar. 2020. Disponivel em: https://www. nexojornal.com.br/expresso/2020/03/24/ coronav\% C $3 \%$ ADrus-os-perigos- de-usar-rem\% C $3 \%$ A g dios - semsupervis\%C3\%A30. Acesso em: 30 mar. 2020.

SOARES, Magda. Letramento: um tema em três gêneros. 4. ed. Belo Horizonte: Autêntica Editora, 2010.

TORRES, Livia. Pesquisa aponta que WhatsApp é a principal fonte de informação de $79 \%$ dos entrevistados. Rádio Senado, Brasília, 12 dez. 2019. Disponivel em: https://www12.senado.leg.br/radio/1/noticia/ pesquisa-aponta-que-whatsapp-e-a-principal-fonte-de-informacaode-79-dos-entrevistados. Acesso em: 30 mar. 2020.
WARDLE, Claire; DERAKHSHAN, Hossein. Information disorder: toward an interdisciplinary framework for research and policy making. Strasbourg: Council of Europe, 2017. Disponivel em: https://rm.coe.int/ information-disorder-toward-an-interdisciplinaryframework-for-researc/168076277c. Acesso em: 25 jul. 2020.

WORLD HEALTH ORGANIZATION (WHO). Managing epidemics: key facts about major deadly diseases. Geneva: World Health Organization, 2018. Disponivel em: https://www.who.int/ emergencies/diseases/managing-epidemics-interactive.pdf. Acesso em: 23. jul. 2020.

ZAROCOSTAS, John. How to fight an infodemic. The Lancet, London, v. 395, fev. 2020. Disponivel em: https://www. sciencedirect.com/science/article/pii/ S014067362030461X?- via\%3Dihub. Acesso em: 22. jul. 2020. https://doi.org/10.1016/S0140-6736(20)30461-X

\section{Gabriela Fernanda Cé Luft}

Doutora em Letras pela Universidade Federal do Rio Grande do Sul (UFRGS), em Porto Alegre, RS. Brasil. Professora de Lingua Portuguesa e Literatura Brasileira no Instituto Federal de Educação, Ciência e Tecnologia do Rio Grande do Sul (IFRS) - Campus Porto Alegre, em Porto Alegre, RS, Brasil.

\section{Filipe Xerxeneski da Silveira}

Mestre em Educação em Ciências: Química da Vida e Saúde pela Universidade Federal do Rio Grande do Sul (UFRGS), em Porto Alegre, RS, Brasil. Doutorando em Educação em Ciências: Química da Vida e Saúde pela Universidade Federal do Rio Grande do Sul (UFRGS), em Porto Alegre, RS, Brasil. Bibliotecário do Instituto Federal de Educação, Ciência e Tecnologia do Rio Grande do Sul (IFRS) - Campus Porto Alegre, em Porto Alegre, RS, Brasil.

\section{Endereço para correspondência}

Gabriela Fernanda Cé Luft

Instituto Federal de Educação, Ciência e Tecnologia do Rio Grande do Sul

Campus Porto Alegre

Rua Cel. Vicente, 281

Centro, 90030041

Porto Alegre, RS, Brasil

Filipe Xerxeneski da Silveira

Instituto Federal de Educação, Ciência e Tecnologia do Rio Grande do Sul

Campus Porto Alegre

Rua Cel. Vicente, 281

Centro, 90030041

Porto Alegre, RS, Brasil 